\title{
Synthesis and Thermal Behaviour of an Amorphous Solid Polymer Electrolyte
}

\author{
Paula C. Barbosa, Luísa C. Rodrigues, M. Manuela Silva*, Michael J. Smith, Marta \\ Costa \\ Centro de Química, Universidade do Minho, Gualtar, 4710-057 Braga, Portugal \\ *nini@quimica.uminho.pt
}

\begin{abstract}
In this study the synthesis of an amorphous polymer network, poly[oxymethylene-oligo(oxyethylene)], designated as aPEO, is described. This polymer has been characterized by gel permeation chromatography, thermal analysis, conductivity measurements, evaluation of electrochemical stability and nuclear magnetic resonance spectroscopy. The synthetic procedure developed permits partial fractionation of the product of the polymerization reaction. This linear macromolecule appears to be a promising polymer for application in batteries and electrochromic devices since it provides access to an amorphous polymer structure with good mechanical properties and promising electrochemical behavior.
\end{abstract}

\section{Introduction}

During the past decade the growing market for high energy density primary and secondary batteries has promoted research and development in lithium battery technologies. The sub-segment of devices using polymer electrolytes is attracting increasing attention and promising applications in lithium-ion batteries, supercapacitors and electrochromic devices (ECD) have attracted particular interest (1). The main advantages of these electrolytes include favourable mechanical properties, ease of fabrication as thin films with suitable dimensions and an ability to form and maintain effective electrode-electrolyte contacts. Although electrolytes based on lithium salts and high-molar-mass poly(oxyethylene oxide) (PEO) have been studied extensively, crystallization of the host polymer limits the conductivity that unplasticized systems may sustain at ambient temperatures $\left(\sigma<10^{-7} \mathrm{Scm}^{-1}\right.$ at $\left.25^{\circ} \mathrm{C}\right)$. Various approaches have been explored to increase room temperature conductivity, including the use of interpenetrating blends, block, comb-branched and crosslinked polymer architectures and plasticizing additives (2). While significant advances have been made in understanding the factors that influence the behavior of this sub-class of solid electrolytes, it has been difficult to produce polymers with sufficiently high conductivity for commercialization of practical devices operating at ambient temperatures. In their search for improved conductivity and stable mechanical properties most authors have directed their attention to amorphous host polymers (3-6). 


\section{Experimental}

\subsection{Synthesis}

The synthesis of oxymethylene-linked polyethylene glycol (PEG400) was carried out using a procedure similar to that previously published by other authors (3). Finely ground $\mathrm{KOH}\left(40 \mathrm{~g}\right.$ ) was mixed with dry $\mathrm{CH}_{2} \mathrm{Cl}_{2}$ (Aldrich Chromasolv for HPLC, 20 $\mathrm{mL}$ ) under nitrogen at room temperature within a three-necked round-bottomed flask equipped with a liquid addition funnel and a condenser. The mixture was stirrer into a slurry using a high-torque overhead motor (Heidolph, RZR 2020), 20 mL PEG400 was added quickly and stirring was continued.

The reaction mixture turned a lemon yellow colour and an increase in viscosity was apparent almost immediately. The temperature of the reaction mixture rose shortly after the addition of the PEG400 and remained constant for the first 15 minutes of the reaction. During this period the viscosity of the reaction mixture became so high that further addition of $5 \mathrm{~mL}$ aliquots of $\mathrm{CH}_{2} \mathrm{Cl}_{2}$ became necessary. Occasional addition of solvent was continued to maintain the viscosity of the reaction volume approximately constant. Typically about $100-150 \mathrm{~mL} \mathrm{CH}_{2} \mathrm{Cl}_{2}$ was added over a period of 5 hours. Finally a volume of $200-250 \mathrm{~mL}$ of $\mathrm{CH}_{2} \mathrm{Cl}_{2}$ was added to quench the reaction.

About $700 \mathrm{~mL}$ of $\mathrm{CH}_{2} \mathrm{Cl}_{2}$ was added and the reaction mixture was filtered at a water pump to separate un-reacted $\mathrm{KOH}$ from the polymer component. The filtrate was reduced in volume to isolate a rubbery transparent polymer with a slight yellow coloration.

The sample $(\approx 5 \mathrm{~g})$ was then purified by dissolution with stirring in a volume of 100 $\mathrm{mL}$ toluene (Acros Organics, water $<30 \mathrm{ppm}$ ) and re-precipitated by addition of about 27 $\mathrm{mL}$ hexane (LabScan, 99\% HPLC). The mixture was heated to re-dissolve the polymer and allowed to cool again to re-precipitate high molecular mass polymer. The precipitated polymer was isolated by decantation and evaporated to dryness. The objective of this procedure was to eliminate any insoluble polymer and to remove the low molecular mass fractions by retention in the mixed solvent fraction.

The polymer obtained from this preliminary treatment was subjected to further purification by tangential flow filtration. A dilute aqueous solution of the polymer was recirculated through a membrane (OMEGATM Filtron Technology Corp.) using a miniUltrasette filter with a flow rate adjusted to permit about $150 \mathrm{~mL}$ of waste fraction to be removed from the filtrate port per hour. This stage of the purification procedure typically took about 24 hours.

The aqueous solution was finally extracted with a similar volume of $\mathrm{CH}_{2} \mathrm{Cl}_{2}$. The polymer was isolated by reduction to dryness on a rotary evaporator and stored in a dessicator over $\mathrm{P}_{2} \mathrm{O}_{5}$ to remove residual water.

\subsection{Thermal analysis}

Samples for thermogravimetric studies were transferred to open platinum crucibles and analyzed using a Rheometric Scientific TG 1000 thermobalance operating under a flowing argon atmosphere between $30^{\circ} \mathrm{C}$ and $700^{\circ} \mathrm{C}$. A heating rate of $10^{\circ} \mathrm{C} \cdot \mathrm{min}^{-1}$ was used to analyze all polymer samples. Polymer samples were also subjected to 
differential thermal analysis under a flowing argon atmosphere with a Mettler DSC 821e using various thermal programs. Samples removed from the host polymer batch were annealed at $-25^{\circ} \mathrm{C}$, both with slow cooling and quenching. In these experiments the extrapolation of onset temperatures for the thermal events was complicated by the proximity of consecutive events and therefore peak temperatures were used to identify events. Although this procedure is not normally applied in thermal analysis, when thermal events are not sufficiently well resolved it represents the only viable method.

\subsection{Impedance spectroscopy}

The conductivity of the polymer was determined using a constant volume support equipped with gold blocking electrodes and located within a Buchi TO 50 oven. The sample temperature was evaluated by means of a type $\mathrm{K}$ thermocouple placed close to the electrolyte film and impedance measurements were carried out at frequencies between $65 \mathrm{kHz}$ and $500 \mathrm{mHz}$ using an Autolab PGSTAT-12 (Eco Chemie), over a temperature range from 20 to $90^{\circ} \mathrm{C}$. Measurement of conductivity was effected during heating cycles.

\subsection{Gel permeation chromatography}

The polymer sample was analyzed using conventional gel permeation chromatography (GPC) with a $0.01 \mathrm{M}$ lithium bromide solution in N,N'dimethylformamide as the eluent. A single solution of the sample was prepared by adding $15 \mathrm{~mL}$ of eluent to $30 \mathrm{mg}$ of sample and warming to $80^{\circ} \mathrm{C}$, with shaking, for 90 minutes. The sample was found to be completely soluble and was filtered through a glass fibre pad into auto sampler vials. A Polymer Laboratories PL-GPC 120 equipped with a refractive index detector and a PS-AL-MT autosampler, and a flow rate of 1.0 $\mathrm{mL} / \mathrm{min}$ was used to perform the analysis. Data was collected and analyzed using Polymer Laboratories "Cirrus" software. A Polymer Laboratories PolarGel guard plus and two polarGel-M $30 \mathrm{~cm}$ columns operating at $80^{\circ} \mathrm{C}$ were used.

\subsection{Electrochemical stability}

Evaluation of the electrochemical stability window of the polymer was carried out within a dry argon-filled glovebox using a two-electrode cell configuration with a gold microelectrode as working electrode. The preparation of the $25 \mu \mathrm{m}$ diameter gold microelectrode surface by the conventional polishing routine was completed outside the glovebox. The microelectrode was then washed with THF, dried with a hot-air blower and transferred into the glovebox. Cell assembly was initiated by locating a freshly-cleaned lithium disk counter electrode (10 $\mathrm{mm}$ diameter, $1 \mathrm{~mm}$ thick, Aldrich, $99.9 \%$ purity) on a stainless steel current collector. A thin-film sample of electrolyte was centered over the counter electrode and the cell assembly completed by locating and supporting the microelectrode in the centre of the sample disk. The assembly was held together firmly with a clamp and electrical contacts were made to the Autolab PGSTAT-12 (Eco Chemie) used to record voltammograms at a scan rate of $100 \mathrm{mVs}^{-1}$. Measurements were conducted at room temperature within a Faraday cage located inside the measurement glovebox. 


\subsection{Nuclear magnetic resonance spectroscopy (NMR)}

The NMR spectrum was recorded on a Bruker Avance $3400\left({ }^{1} \mathrm{H}: 400 \mathrm{MHz},{ }^{13} \mathrm{C}: 100\right.$ $\mathrm{MHz}$ ) at room temperature and $\mathrm{CDCl}_{3}$ was used as solvent. The chemical shifts are expressed in $\delta(\mathrm{ppm})$ from TMS.

\section{Thermal properties}

\section{Results and discussion}

Multiple melting peaks have been reported (4-7) in several semi-crystalline polymer networks based on blends with different components, chain lengths and crystal forms or in single component systems in which crystal perfecting or recrystallization occurs during melting. In general the structure adopted by semi-crystalline polymers is very sensitive to thermal history and to the presence of additives that may influence crystallization kinetics. The thermal behavior of the polymer host is illustrated in Figures 1 to 3 . The DSC curves included in Figure 1 represent different thermal studies of the polymer host matrix. These results are similar to those reported by Nicholas (8). The sequence of events observed in curve a) on heating as-prepared polymer samples is consistent with melting of unstable crystals at $\mathrm{T}_{\mathrm{m} 1} \approx-6^{\circ} \mathrm{C}$, followed closely by recrystallization at $\mathrm{T} \approx-1^{\circ} \mathrm{C}$. More stable crystals melt at $\mathrm{T}_{\mathrm{m} 2}$ close to $10^{\circ} \mathrm{C}$ with recrystallization or crystal perfecting causing a shoulder and a third peak at $14{ }^{\circ} \mathrm{C}$. The effects of annealing were investigated and results are presented in curve b). Annealing the sample close to the melting temperature for $2 \mathrm{~h}$ resulted in a DSC curve dominated by a single melting peak at $9^{\circ} \mathrm{C}$. The value of the $\mathrm{T}_{\mathrm{m}}$ for the annealed sample is close to that reported for PEG400 $\left(\mathrm{T}_{\mathrm{m}}=8^{\circ} \mathrm{C}\right)$. The heat of fusion $\left(\Delta \mathrm{H}_{\text {fus }}\right)$ of the polymer matrix prepared, $39.97 \mathrm{Jg}^{-1}$, was determined for the annealed sample and is quite low in comparison with the values of the thermodynamic enthalpy of fusion of poly(oxyethylene oxide) $\left(\Delta \boldsymbol{H}_{\text {fus }}^{0}=210 \mathrm{Jg}^{-1}\right)(9)$. Based on the enthalpy of melting of perfectly crystalline poly(oxyethylene oxide), the degree of crystallinity of the aPEO produced was estimated at about 19\%. At room temperature, this polymer is a completely amorphous material (Figure 2). Figure 3 is included to illustrate the effect of thermal history and heating rate on the polymer samples. At low heating rates, as a result of recrystallization during heating, the endotherm of the more stable component was resolved as the major peak. This observation is consistent with the results reported by Y. Pang and co-workers (10). At faster heating rates broader multiple melting peaks are observed. The Tg of the polymer host occurs at temperatures close to the operating limit of the equipment and therefore it was not possible to determine Tg temperature with precision. A value of $\mathrm{Tg}$ below $-60^{\circ} \mathrm{C}$ is however in agreement with results presented by other groups $(8,11,12)$. Thermal degradation of this host polymer takes place in two stages (insert in Figure 2), with onset of thermal decomposition at about $250^{\circ} \mathrm{C}$. 


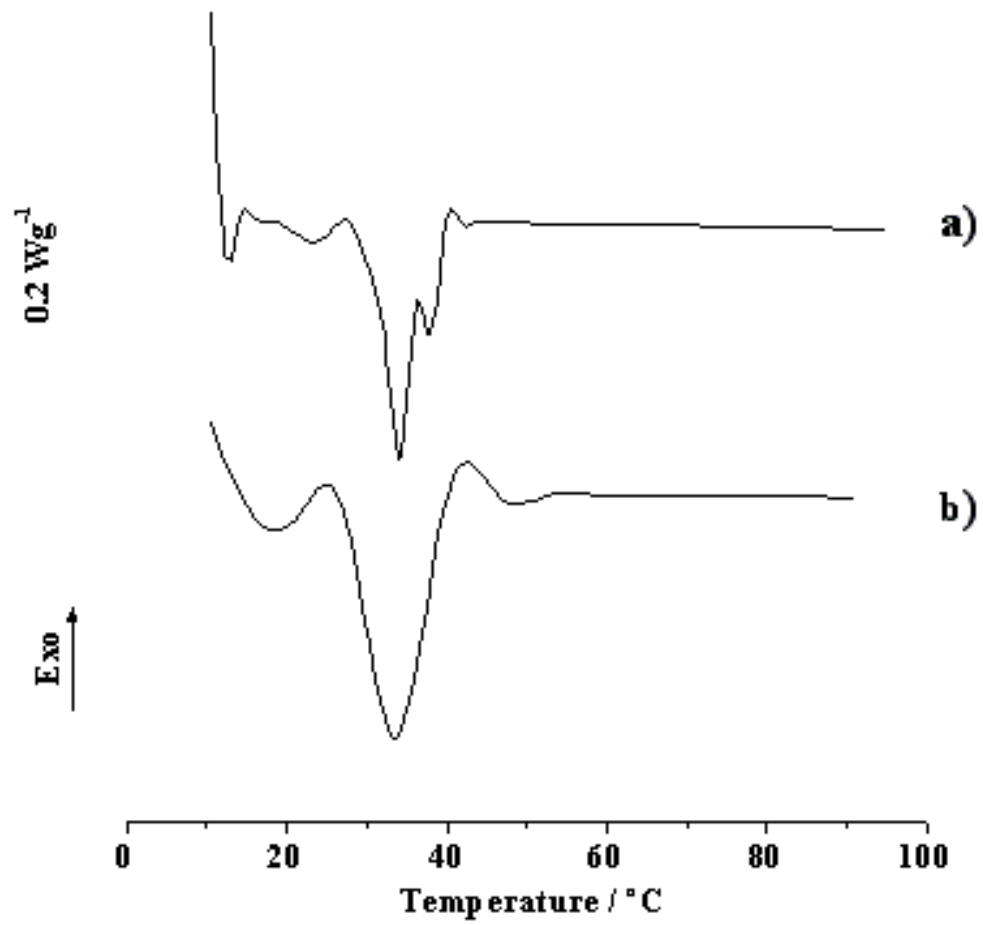

Figure 1. DSC curves for samples of aPEO matrix: a) quenched sample, b) annealed sample.

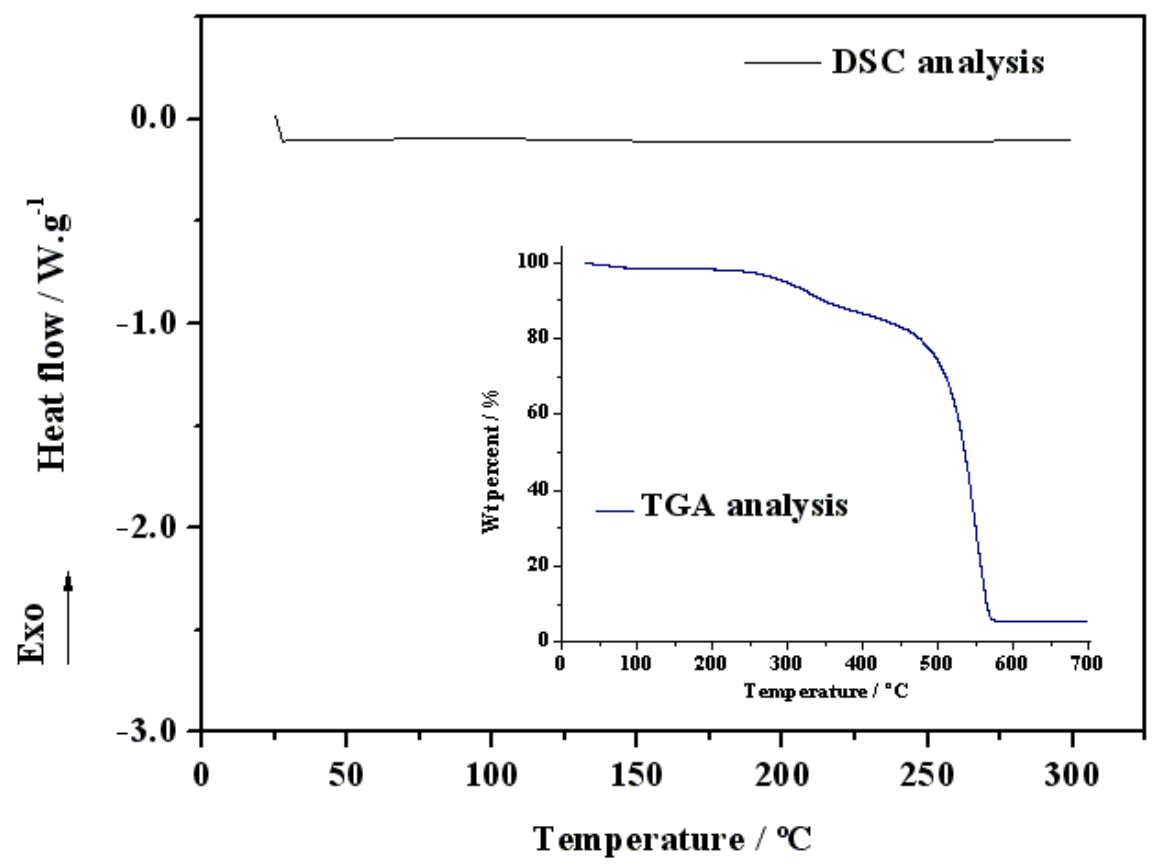

Figure 2. Differential scanning calorimetry curve of aPEO. Thermogravimetric curve (inset). 


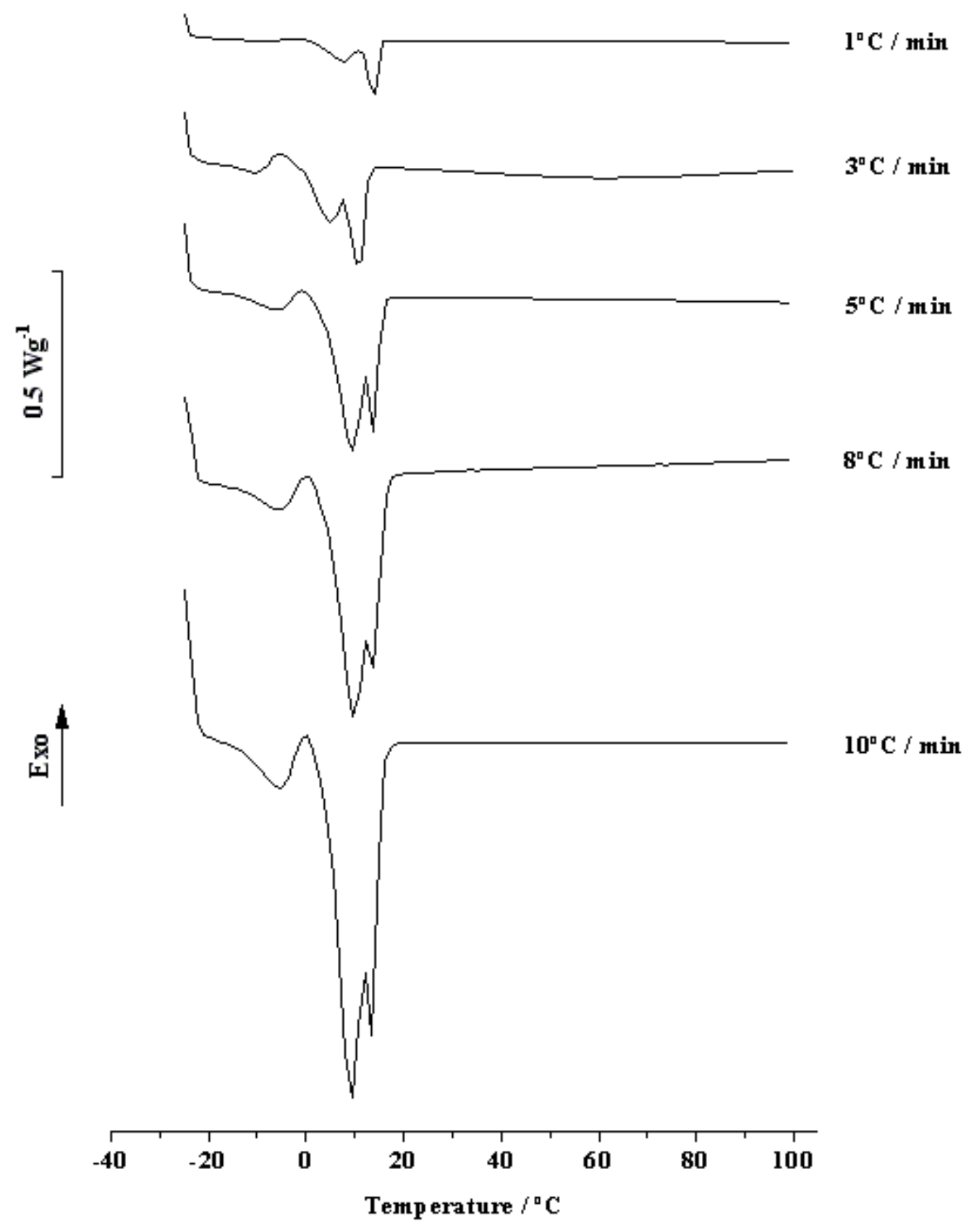

Figure 3. DSC analysis of aPEO samples at different heating rates. All samples were cooled to $-25^{\circ} \mathrm{C}$ and heated at $5^{\circ} \mathrm{C} \cdot \mathrm{min}^{-1}$.

\section{Electrochemical behaviour}

Total ionic conductivity is an critical performance parameter for electrolytes intended for application in electrochromic devices, such as smart windows, displays, or indeed in lithium batteries. In all these devices the electrolyte must be sufficiently robust in order to perform adequately as a mechanical separator between the device electrodes. At the same time it must also be electrochemically, chemically and thermally stable so that it may continue to perform over a reasonable device lifetime. 
The temperature dependence of conductivity of the un-doped aPEO host is shown in Figure 4. The host polymer prepared was found to dissolve guest ionic species and to exhibit non-linear behavior indicative of the presence of an amorphous morphology. This observation is consistent with results of thermal analysis. The level of conductivity of the undoped polymer at room temperature was $6.88 \times 10^{-8} \mathrm{Scm}^{-1}$ confirms that in the absence of added guest ionic species this material has a very low residual conductivity, possibly due to the presence of ionic species that remain from the synthetic procedure.

The data presented in Figure 5 demonstrate that the total ionic conductivity is substantially increased as a result of addition of guest salt species. Although several salts have been studied, only the results obtained with two compositions of $\mathrm{LiClO}_{4}$ are reported in Figure 5. In accordance with the conventional notation used in solid polymer electrolytes, the concentration of salt in the electrolyte is expressed as $\mathrm{n}$, the molar ratio of oxygen atoms in the polymer chain to guest lithium ions.

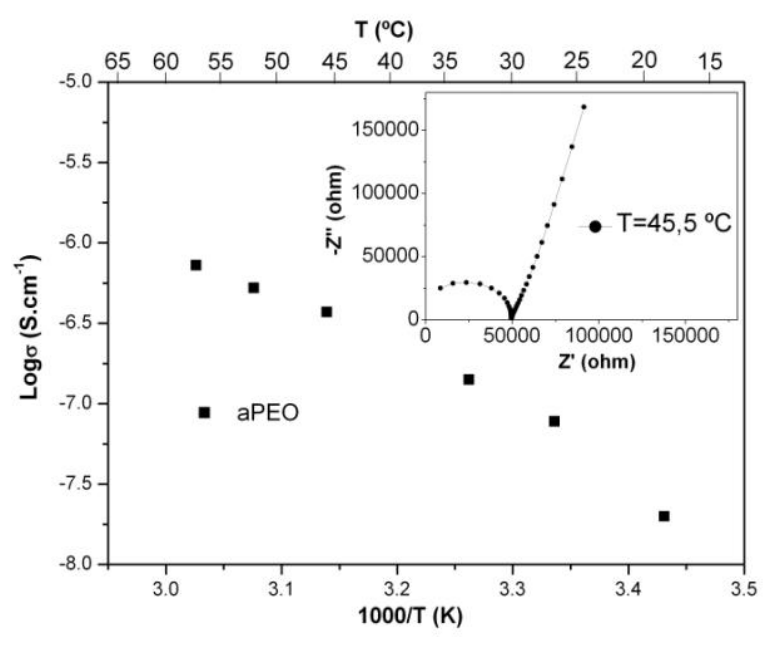

Figure 4. Arrhenius plot of logarithm of conductivity versus reciprocal temperature of aPEO.

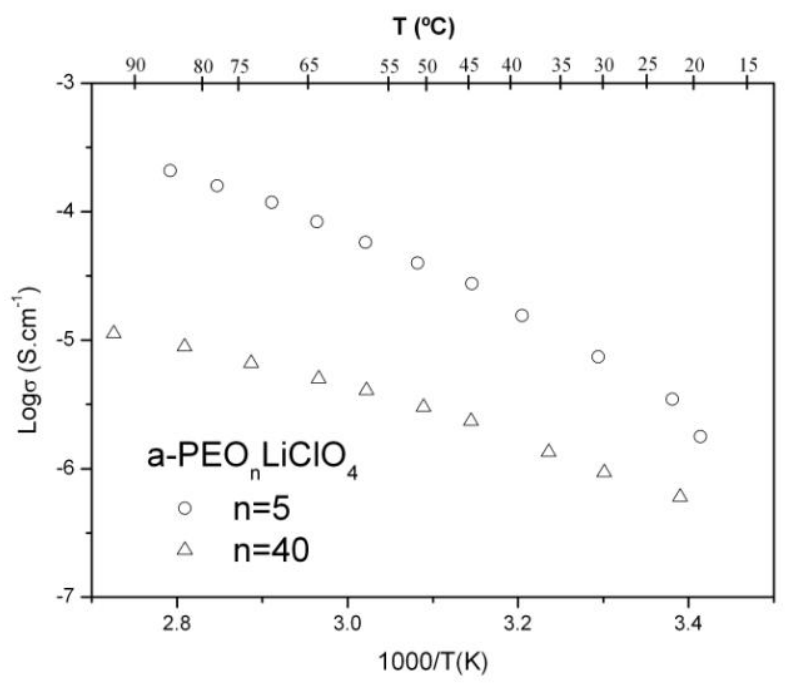

Figure 5. Arrhenius plot of logarithm of conductivity versus reciprocal temperature of $\mathrm{aPEO}_{\mathrm{n}} \mathrm{LiClO}_{4}$.

Gel permeation chromatography 
GPC curves of aPEO in Figure 6 show a single peak and confirm the efficiency of the purification procedure applied. Results for $\mathrm{Mw}, \mathrm{Mn}$ and polydispersity are included in Table 1. Previous preparations of this polymer host have shown a small peak at low molecular weight attributable to ring polymers and a large peak at high molecular weight attributable to linear chains $(8,14)$. Using the purification procedure described in this paper only high molecular weight polymer was obtained.

Table 1. Mw , Mn and polydispersity of aPEO.

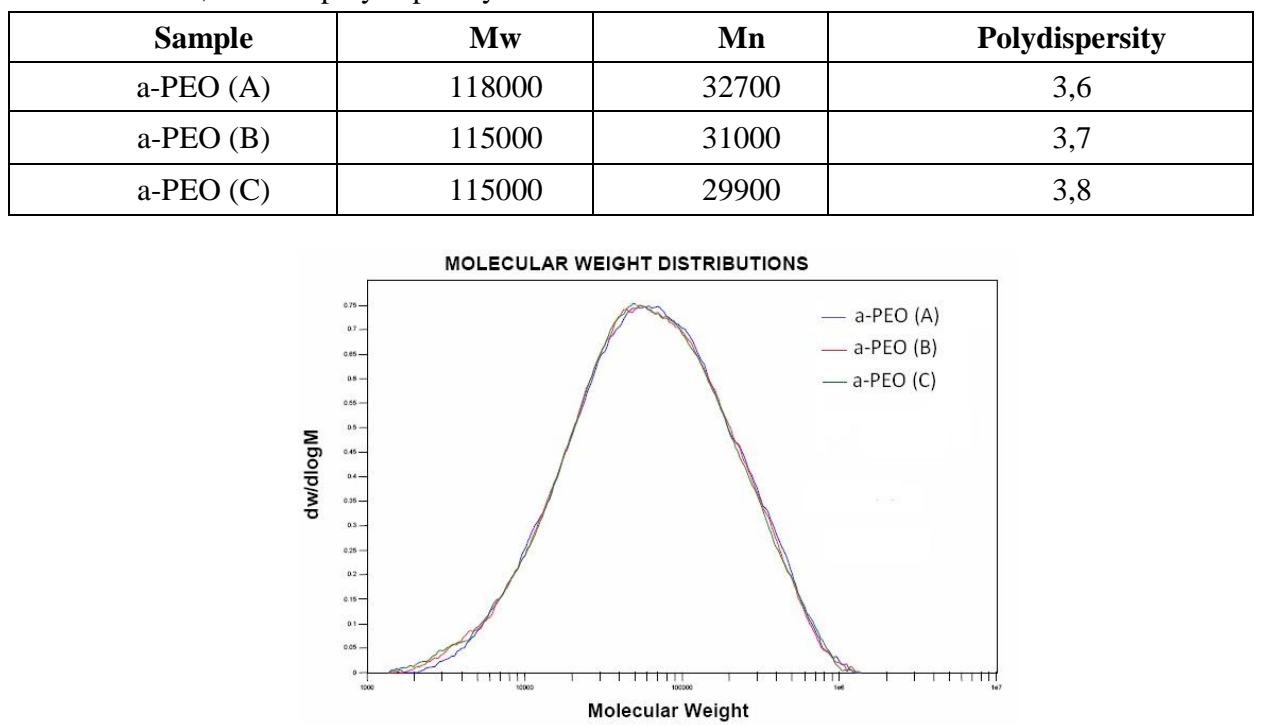

Figure 6. GPC curves of aPEO.

\section{Electrochemical Stability}

The electrochemical stability range of aPEO was characterized by microelectrode cyclic voltammetry over the potential range between -1.0 and $6.0 \mathrm{~V}$ (Figure 7). In the anodic region, the sample was found to be stable up to about $4.5 \mathrm{~V}$ versus $\mathrm{Li} / \mathrm{Li}^{+}$. These results suggest that the electrolyte shows a suitable performance for primary and secondary cells operating at potentials below $4.5 \mathrm{~V}$. 


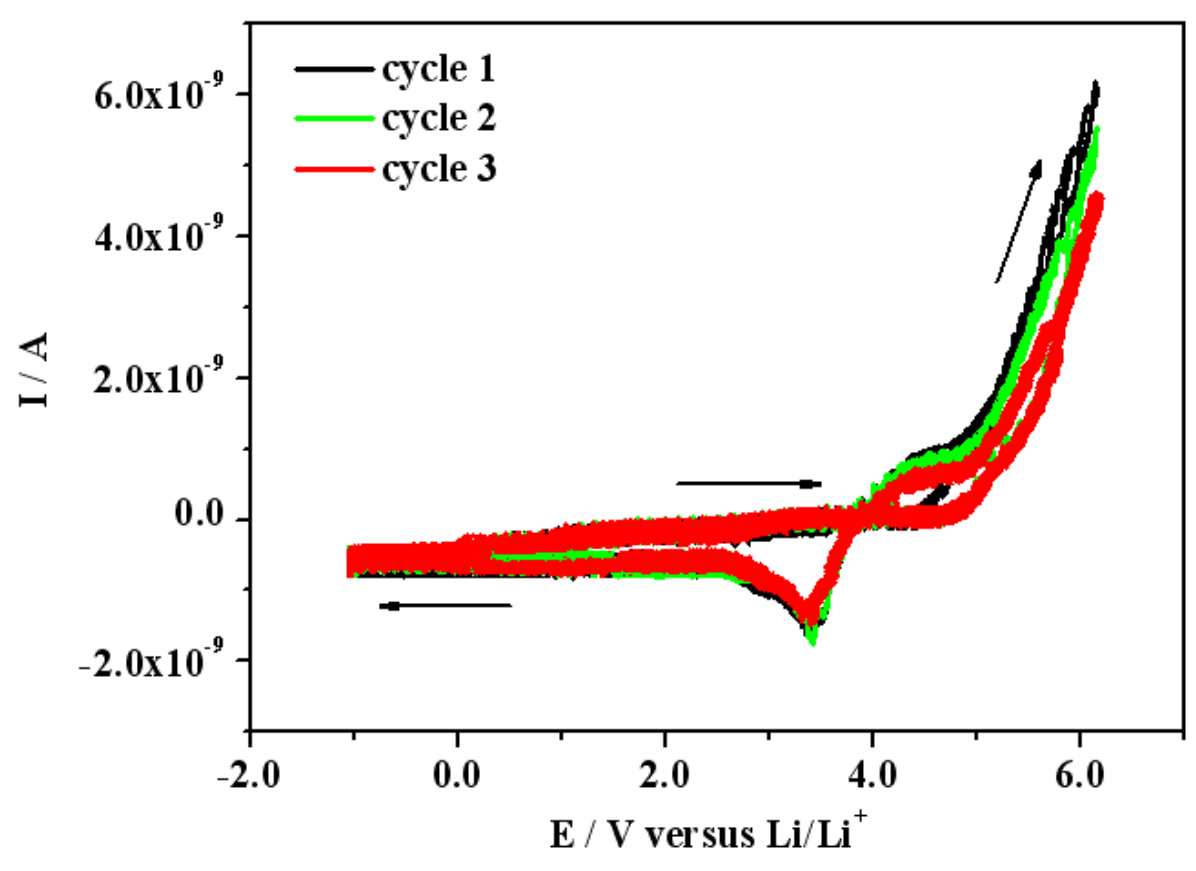

Figure 7. Voltammogram of the polymer at a $25 \mu \mathrm{m}$ diameter gold microelectrode vs. $\mathrm{Li} / \mathrm{Li}+$. Initial sweep direction is anodic and sweep rate is $100 \mathrm{mVs}^{-1}$.

\section{Nuclear magnetic resonance spectroscopy (NMR)}

The ${ }^{1} \mathrm{H}$ and ${ }^{13} \mathrm{C}$ NMR spectrum obtained with the host polymer matrix were similar to those reported previously for high-molecular-weight polymers (6). In the ${ }^{1} \mathrm{H}$ NMR spectrum (Figure 8) the alkyl protons are observed as a multiplet at $\delta 3.62-3.72 \mathrm{ppm}$ and the proton of the hydroxyl group as a singlet at $\delta 4.73 \mathrm{ppm}$. The ${ }^{13} \mathrm{C}$ NMR spectrum (Figure 9) shows six different alkyl carbon atoms ( $\delta 66.84 \mathrm{ppm}, 70.29 \mathrm{ppm}, 70.42 \mathrm{ppm}$, 70.52ppm, 70.62ppm, 95.52ppm) linked to oxygen atoms. 


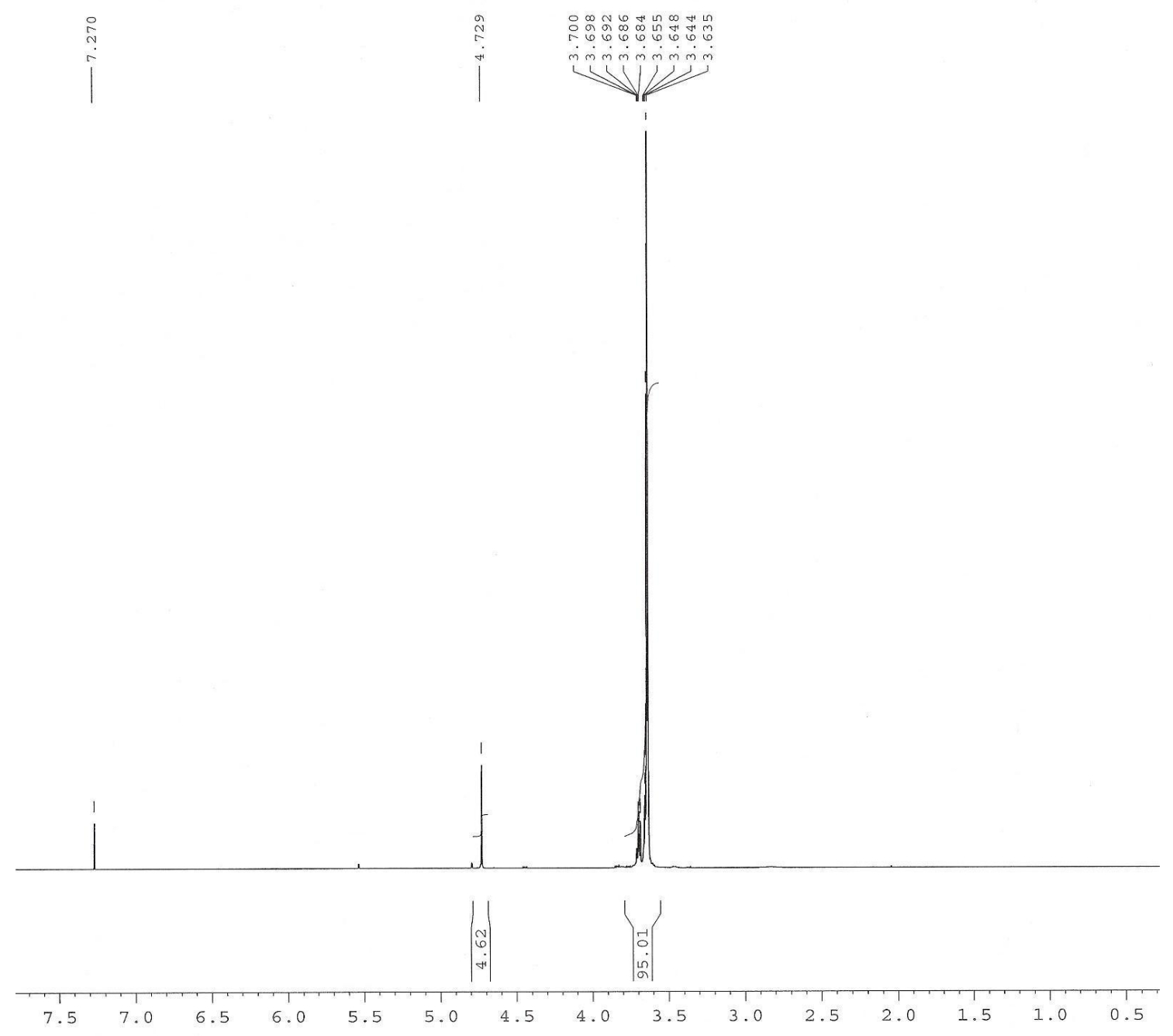

Figure $8 .{ }^{1} \mathrm{H}$ NMR spectra of aPEO matrix. 


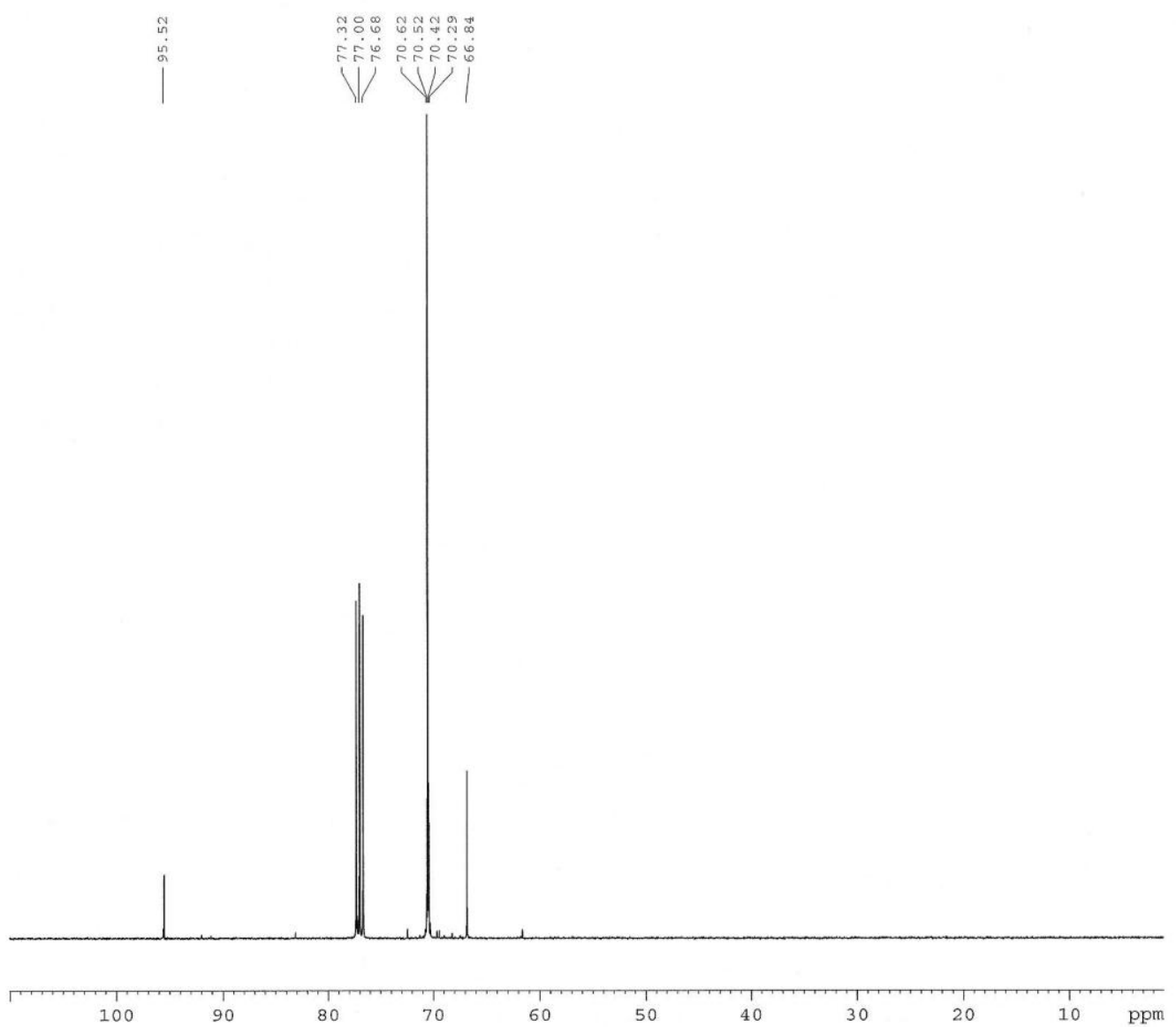

Figure $9 .{ }^{13} \mathrm{C}$ NMR spectra of aPEO matrix.

\section{Conclusions}

In this study we describe the preparation of an amorphous polymer host with good thermal stability and appropriate electrochemical and mechanical properties. Preliminary characterization of both the un-doped aPEO host material and electrolytes prepared with selected lithium guest salts confirmed an encouraging performance relative to semi-crystalline electrolytes prepared using commercial poly(ethylene oxide). The introduction of a final purification stage based on the tangential flow filtration technique permits removal of low molecular weight fractions and the production of a high molecular weight polymer with significantly improved mechanical behavior. The performance of electrolytes based on this material compares very favorably with that of samples prepared without the final purification step.

\section{Acknowledgements}

The authors are pleased to acknowledge the help provided by F.M. Gray (University of St. Andrews, UK) in the initial stages of development of the purification method, and support provided by the University of Minho and the Fundação para a Ciência e a Tecnologia (contracts POCI/QUI/59856/2004, POCTI/SFA/3/686) for laboratory equipment and research staff grants (contracts SFRH/BD/22707/2005, 
SFRH/BD/38616/2007 and SFRH/BD/31531/2006). LCR expresses her gratitude for financial support from the Batteries Division of the 216th ECS conference.

\section{References}

1. F. M. Gray, in Solid Polymer Electrolytes: Fundamentals and Technological Applications, VCH Publishers, Inc. (1991).

2. J.R. MacCallum, C.A.Vincent, Polymer Electrolyte Reviews, vol. 1, Elsevier, London, 1987.

3. J.R. Craven, R.H Mobbs, C. Booth, J.R.M. Giles, Makromol Chem Rapid Commun 7, 81 (1986).

4. J. Scheirs, "Compositional and failure analysis of polymers: a practical approach", John Wiley \& Sons, Chichester, England, p.122-125 (2000).

5. J. D. Menczel, R. Bruce Prime, "Thermal Analysis of Polymers, Fundamentals and Applications", John Wiley \& Sons, Oxford, UK, p. 105-110 (2009).

6. C. Passingham, P. J. Hendra, M. E. A. Cudby, V. Zichy, M. Weller, European Polymer Journal, 26, 631-638 (1990).

7. N. P. Cheremisinoff, "Handbook of Polymer Science and Technology: Synthesis and properties", Marcel Dekker, Inc., New York, p. 492-493 (1989)

8. C. V. Nicholas, D. J. Wilson, C. Booth, J. R. M. Giles, Br. Polym J. 20:289, (1988).

9. C. Booth, C. V. Nicholas, D. J. Wilson in Polymer Electrolyte Reviews - 2, ed. J. R. MacCallum and C. A. Vincent, Elsevier, New York, p.229 (1989)

10. Y. Pang, S.-M. Mai, K.-Y. Huang, Y.-Z. Luo, J. H. Thatcher, R. A. Colley, C. V. Nicholas, C. Booth, J. Mater. Chem. 5, 831, (1995).

11. J. R. Craven, R. H. Mobbs, C. Booth, Makromol. Chem. Rapid Commun., 7, 81 (1986).

12. S. Nagae, H. M. Nekoomanesh, C. Booth, Solid State Ionics, 53-56, 1118, (1992).

13. J.R. Craven, C. V. Nicholas, R. Webster, D. J. Wilson, R. H. Mobbs, G. A. Morris, F. Heatley, C. Booth, J.R.M.Giles, Br Polym. J. 19, 509 (1987).

14. M. Nekoomanesh, C. Booth, Iranian J. Polym. Science, 1, 36 (1992). 